\title{
Percepção e valoração ambiental em áreas verdes no Município de Palotina, Estado do Paraná, Brasil
}

\section{Heloisa Caroline Mariano da Silva ${ }^{1}$, Fabiana Pereira Ferreira $^{1}$, Leticia Oliveira Mendes $^{1}$ e Valéria Ghisloti Iared $^{2}$}

${ }^{1}$ Universidade Federal do Paraná. Curso de Bacharelado em Ciências Biológicas. Rua Pioneiro, 2153. Jardim Dallas. Palotina-PR, Brasil (CEP 85950-000).

${ }^{2}$ Universidade Federal do Paraná. Departamento de Biodiversidade. Rua Pioneiro, 2153. Jardim Dallas. Palotina-PR, Brasil (CEP 85950-000).

Resumo. Muitos autores e documentos nacionais e internacionais pontuam que a expansão desordenada das cidades e a falta de políticas públicas capazes de ordenar este crescimento com a manutenção das áreas verdes estão relacionadas aos problemas urbanos enfrentados na atualidade, os quais causam sérios prejuízos à saúde física e mental da população. Diversos estudos ressaltam a compreensão da percepção ambiental dos moradores como possibilidade para entendimento das relações existentes entre sociedade e ambiente, já que a população tem papel fundamental em relação à tomada de decisões que envolvem a gestão de áreas verdes, pois a participação desta fornece transparência à política urbana. A investigação objetivou analisar a percepção da população usuária de três áreas verdes urbanas do município quanto aos usos e funções do espaço. A coleta de dados foi realizada por meio de uma entrevista estruturada, a qual era composta por perguntas que identificavam o perfil dos participantes e por cartas que apresentaram 12 atributos socioambientais, 1 - cultural, 2 - lugar histórico, 3 - alimentos e suprimentos, 4 - vínculo afetivo, 5 - melhora física e mental, 6 - paisagens, cheiros e sons, 7 - aprendizado sobre o meio ambiente, 8 - futuro, 9 - lazer e atividades, 10 - extração e caça, 11 - diversidade, 12 - lugar religioso e espiritual, as quais foram apresentadas aos usuários do espaço para que ordenassem uma sequência que variasse do "atributo mais importante" para "atributo menos importante" de acordo com o seu sentimento e opinião pessoal. Posteriormente, os dados foram sistematizados e analisados segundo o perfil dos usuários. Apesar da especificidade de cada espaço, os resultados indicam que os residentes (na maioria mulheres) usufruem rotineiramente das áreas verdes urbanas nas mais diversas atividades (atividades físicas, culturais, recreativas e educativas).

Palavras-chave: Sustentabilidade; Plano diretor; Praças urbanas.

Recebido

14/02/2020

Aceito

28/07/2020

Disponível on line 09/08/2020

Publicado $31 / 08 / 2020$

Acesso aberto

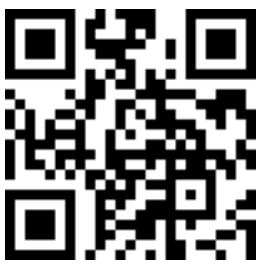

ORCID

(1) 0000-0002-0898-2980 Heloisa Caroline Mariano da Silva (D) 0000-0003-4545-472X Fabiana Pereira Ferreira

(D) 0000-0001-6487-1380 Leticia Oliveira Mendes

D 0000-0002-1082-9870 Valéria Ghisloti Iared

ISSN 2359-1412/RBGAS-2020-0023/2020/7/16/22/771

Rev. Bras. Gest. Amb. Sustent.

http://revista.ecogestaobrasil.net 
Abstract. Environmental perception and valuation in green
areas in Palotina Municipality, Paraná State, Brazil. Many authors and national and international documents point out that the disorderly expansion of cities and the lack of public policies capable of ordering this growth with the maintenance of green areas are related to the urban problems faced nowadays, which cause serious damage to physical and mental health. Several studies highlight the comprehension of the residents' environmental perception as a possibility for understanding the existing relations between society and the environment, since the population has a fundamental role in relation to decision-making involving the management of green areas once their participation provides transparency to the policy urban. The investigation aimed to analyze the perception of the user population of three urban green areas in the town regarding the uses and functions of the space. Data collection was carried out through a structured interview, which consisted of questions that identified the profile of the participants and letters that presented 12 socioenvironmental attributes, 1 - cultural, 2 - historical place, 3 - food and supplies, 4 - affective bond, 5 - physical and mental improvement, 6 - landscapes, smells and sounds, 7 - learning about the environment, 8 - future, 9 - leisure and activities, 10 - hunting and extraction, 11 - diversity, 12 - religious and spiritual place; which were presented to users of the space to order a sequence that ranged from "most important attribute" to "least important attribute" according to their personal feeling and opinion. Subsequently, the data were systematized and analyzed according to the users' profile. Despite the specificity of each space, the results indicate that residents (mostly women) routinely enjoy urban green areas in the most diverse activities (physical, cultural, recreational and educational activities).

Keyword: Sustainability; Master plan; Urban squares.

\section{Introdução}

\section{Áreas verdes}

A população brasileira está crescendo rapidamente e as cidades estão cada vez mais sendo ocupadas de maneira desordenada, ocasionando impacto para o meio ambiente e prejudicando a qualidade de vida da população. Segundo previsões da Organização das Nações Unidas (ONU, 2019), espera-se que em 2050 as cidades de 55\%, passem a abrigar $70 \%$ da população mundial.

Com o aumento populacional ocorre também a ocupação desordenada do solo urbano, e com isso a redução da cobertura vegetal urbana, que acaba prejudicando a qualidade de vida da população (Ribeiro, 2009; Costa e Colesanti, 2011; Barros et al. 2015). Deste modo, se torna necessário buscar formas de amenizar os efeitos provocados pelas grandes populações nas cidades, principalmente em locais que foram ocupados de maneira desordenada, destruindo parte ou quase toda a vegetação nativa desses lugares (Cabral, 2013).

A manutenção das áreas verdes urbanas vem recebendo destaque na literatura nacional e internacional por estar relacionado a qualidade ambiental da população e por 
amenizar as consequências negativas causadas pela urbanização. As funções das áreas verdes podem ser definidas como o conjunto de elementos e atividades que possuem a capacidade de se inter-relacionarem em um determinado espaço, sendo de real importância já que geram benefícios sociais e ecológicos (Bargos e Matias, 2011; Pedrosa e Gaia, 2014).

As áreas verdes acabam por revelar diversos valores na sociedade uma vez estão relacionados ao uso cotidiano da população. As funções podem ser variadas como o convívio social e de lazer; função estética e embelezamento; função ecológica como regulação do clima e qualidade do ar; função educativa como possibilidade de contato com a natureza e função psicológica, a qual que permite a prática de atividades física e relaxamento (Londe e Mendes, 2014).

A relação entre cidades e meio ambiente vem sendo pautada nas políticas públicas brasileiras sendo que o Estatuto das Cidades estabelece o Plano Diretor Municipal como um dos seus instrumentos (Brasil, 2001). O Plano Diretor Municipal traz um conjunto de regras e princípios que orientam a construção e utilização do espaço urbano e contém diretrizes para a preservação e ocupação das áreas verdes municipais que fazem parte do Sistema de Espaços Livres. A Lei no 12.651/2012, que rege a exigência de áreas verdes nos loteamentos e sua aplicação em áreas verdes de recursos oriundos da compensação ambiental (Brasil, 2012), é outra medida legal para a garantia do acesso desses espaços pela população.

Ao analisar o Plano Diretor do Município de Palotina (Palotina, 2019), verifica-se que está previsto que $10 \%$ de cada loteamento devam ser destinados às construções de áreas verdes urbanas. No entanto, estudos exploratórios nestes espaços em Palotina detectaram que menos de $25 \%$ das áreas verdes estão de acordo com o Plano Diretor (Alves et al., 2018).

\section{Percepção ambiental}

De origem latina, perceptione, a perceção pode ser classificada em um despertar de consciência de maneira explícita, em relação a qualquer circunstância ou objeto, sendo a circunstância referente a acontecimentos vivenciados (Mucelin e Bellini, 2008).

De acordo com Marin (2008), um dos mais longínquos assuntos explorados no estudo do ser humano é a percepção, a qual é investigada com o intuito de elucidar as contemplações do mundo ao nosso redor. A percepção ambiental pode ser caracterizada pelo ato de compreender o ambiente em que o ser humano está imerso e essa compreensão pode acarretar vínculos afetivos e posicionamentos políticos relacionados à conservação do ambiente.

Para Tuan (1980), o ser humano percebe o mundo através dos seus sentidos, deste modo, tudo que é percebido forma uma leitura de mundo, onde os sentidos comandam a construção cognitiva. 0 autor discorre sobre dois termos pertencentes ao campo da geografia humanista: topofilia que está relacionado a familiaridade e apego ao lugar, pois topo remete a lugar e filia compete à filiação. Topofobia caracteriza o oposto, pois o radical fobia refere-se à aversão, relacionando o lugar ao medo e a repugnância.

De fato, o significado para cada ser humano é construído com base em suas vivências pessoais e coletivas que refletem em como a pessoa irá interagir e se engajar com sua realidade local. Estudar a percepção ambiental é de essencial importância para compreendermos as inter-relações entre cada indivíduo e o ambiente, entendendo suas expectativas, anseios, satisfações e insatisfações, julgamentos e condutas.

Pesquisas, como as conduzidas por Pereira et al. (2017), demonstram que a percepção ambiental traz a possibilidade de entendimento das relações existentes entre sociedade e ambiente já que esta se liga a processos históricos e socioculturais. A significância particular para cada pessoa a respeito de um determinado local é construída a partir de suas experiências vividas e ressaltam o papel fundamental da sociedade em 
relação à tomada de decisões, envolvendo à gestão ambiental municipal e, em destaque, a gestão de áreas verdes. A participação comunitária em espaços decisórios fornece transparência à política urbana e a sua falta pode resultar na má gestão pública. A falta de conhecimento da população acerca da importância das áreas verdes é um agravante, visto que "o meio ambiente natural foi substituído por espaços urbanos, sendo estes palcos de relações entre a comunidade humana e seu meio físico, alterado pela própria ação antrópica" (Melazo, 2005, p. 48).

Desta forma, encorajar as pessoas a perceberem as suas atitudes diante das áreas verdes urbanas pode levá-las a sensibilização da importância da sua conservação no espaço urbano. Por consequência, analisar a percepção ambiental possibilita interpretar as atitudes e comportamentos e, assim, planejar ações de gestão e educação ambiental em Palotina.

Discorrida a importância das áreas verdes urbanas na literatura e na legislação, o presente trabalho objetivou compreender os usos e funções de três área verdes urbanas de Palotina sob a perspectiva dos residentes.

\section{Metodologia}

\section{Local de estudo}

O estudo foi realizado no município de Palotina, o qual está situado na mesorregião do oeste do Paraná e faz parte da microrregião de Toledo (Figura 1). Na sua área, ocorre o bioma Mata Atlântica e o tipo vegetacional é a Floresta Estacional Semidecidual.

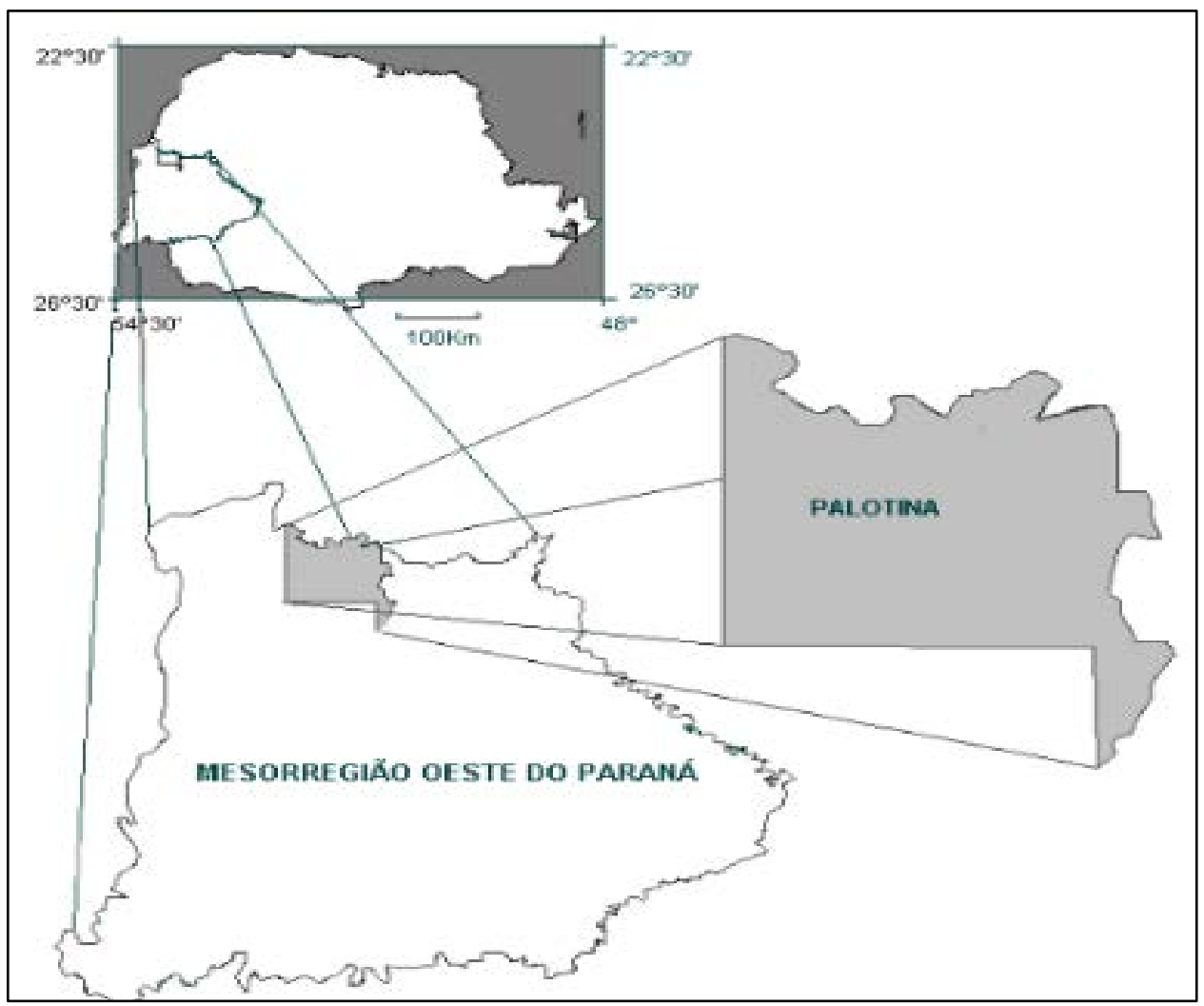

Figura 1. O Município de Palotina, Paraná. Fonte: Belusso e Serra (2006). 
Em meados de 1953, ocorreu a chegada dos primeiros imigrantes no município, sendo eles da região sul do país, mas somente em 1960 a cidade foi fundada. A maior parte do território de Palotina baseia-se na agricultura, seguida de agroindústrias. Devido ao uso do solo, inúmeras áreas naturais foram devastadas e vem sendo substituídas por lavouras e construções para expansão da cidade.

Além do município ter passado por um desmatamento intenso, Palotina é uma região pouco arborizada e caracterizada por possuir clima de temperaturas elevadas, com verões quentes e úmidos e os invernos secos. Para amenizar essas características climáticas, é de suma importância a presença de áreas verdes urbanas (Alves et al., 2018).

Três áreas verdes urbanas foram selecionadas para esse estudo por serem consideradas relevantes historicamente e socialmente pelo Conselho Municipal de Meio Ambiente de Palotina, a saber: Lago Municipal de Palotina, Praça 15 de Novembro (popularmente conhecida como "Praça do Vovô") e Bosque da Rua Dom Pedro I (Figura 2).

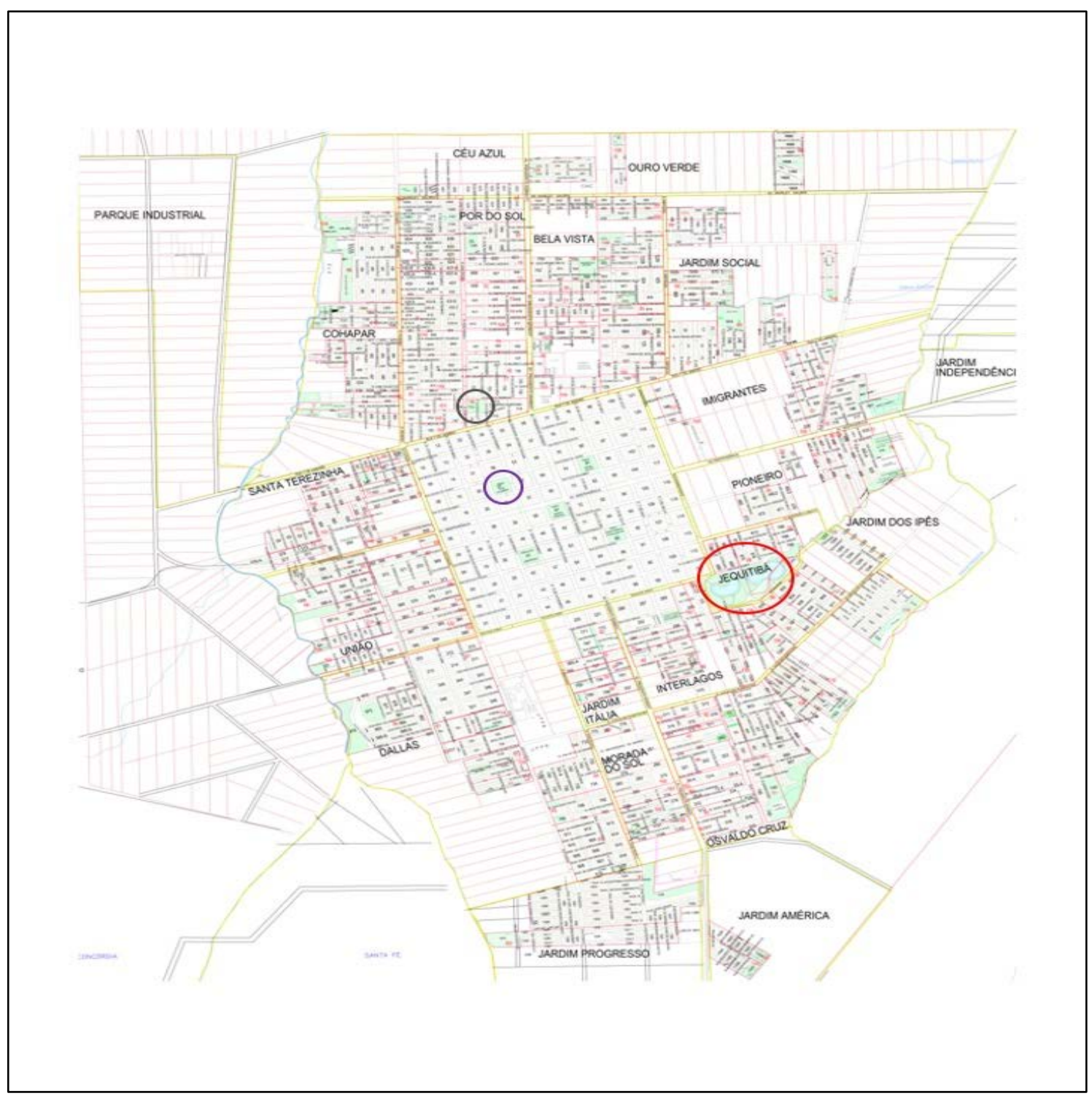

Figura 2. Localização das três áreas verdes estudadas, Lago Municipal de Palotina (vermelho), Praça 15 de Novembro (roxo) e Bosque da Rua Dom Pedro I (cinza). Fonte: Palotina (2019). 


\section{Coleta de dados}

A coleta de dados foi desenvolvida com base no trabalho de Pereira et al. (2017) e envolveu uma análise da relação meio ambiente e população por meio de uma entrevista estruturada contendo algumas informações sobre o perfil do entrevistado (nome, idade e gênero, tempo de residência no bairro, distância que reside da área e com qual frequência utiliza o lugar) e perguntas acerca das características da área.

Após apresentação da proposta do trabalho e explicação da importância das áreas verdes urbanas, os entrevistados foram convidados a realizar um rankeamento de 12 cartas contendo diferentes atributos: 1- cultural; 2- lugar histórico; 3- alimentos e suprimentos; 4- vínculo afetivo; 5- melhora física e mental; 6- paisagem, cheiros e sons; 7- aprendizado sobre o meio ambiente; 8- futuro; 9- lazer, atividades; 10- extração e caça; 11- diversidade; 12- lugar religioso, espiritual. 0 entrevistado ordenou as cartas seguindo o padrão da mais relevante a menos relevante de acordo com sua vivência e opinião formando a sequência que mais fazia sentido para si.

Os dados foram coletados no primeiro semestre de 2019 e para cada área foram obtidos números diferentes de respondentes: Lago Municipal de Palotina (29 entrevistados), Praça 15 de Novembro (30 entrevistados) e Bosque da Rua Dom Pedro I (21 entrevistados). Considerou-se que o número de entrevistas foi suficiente quando houve reincidência das informações, ou seja, as respostas para aquela área começaram a se repetir, não compensando incluir outros participantes (Minayo, 2000).

Com o perfil e sequenciamentos obtidos nas entrevistas, foram elaborados gráficos e tabelas reunindo todas as informações. As respostas foram separadas por categorias, sendo que cada pergunta se tornou uma categoria de resposta e cada categoria gerou um gráfico.

\section{Resultados}

As relações da idade e gênero dos entrevistados podem ser observadas nas Figuras $3,4,5$, os quais indicam que a maioria dos usuários é composto pelo público feminino nas três áreas verdes. No entanto, a faixa etária variou, muito possivelmente, devido ao tipo de atividades propiciadas em cada área verde. Percebeu-se que os usuários entrevistados da Praça 15 de Novembro são em sua maioria idosos, concordando com o nome popular da área, "Praça do Vovô". No Bosque, o perfil foi caracterizado como de mulheres de meia idade que acompanham seus filhos em atividades de lazer enquanto no Lago Municipal, a faixa etária variou de 15 a 80 anos, sendo que a maioria deles tinha entre 51 a 60 anos.

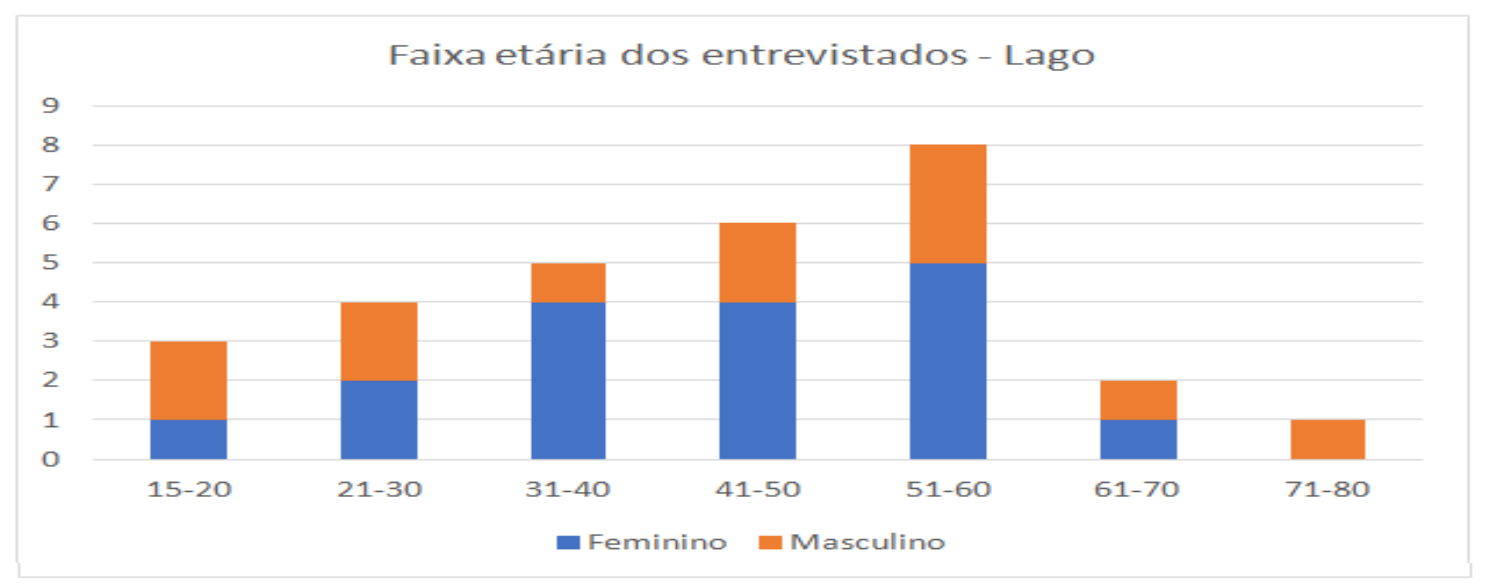

Figura 3. Faixa etária dos entrevistados - Lago Municipal. 


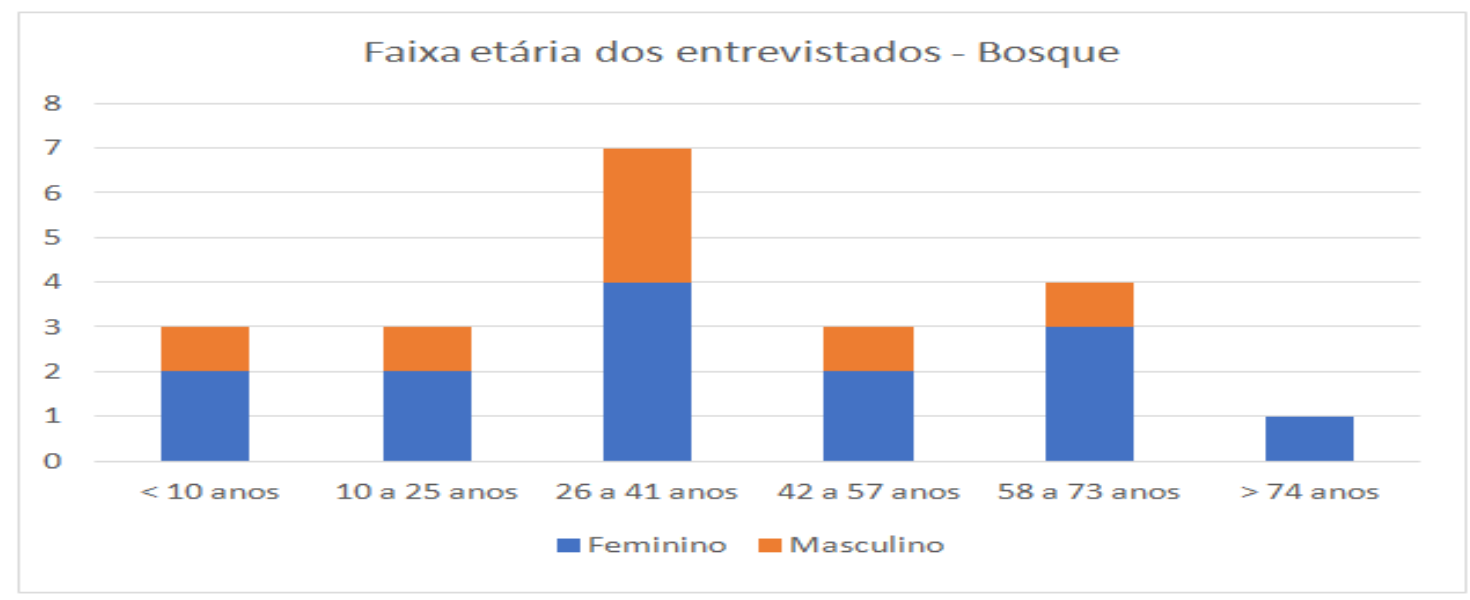

Figura 4. Faixa etária dos entrevistados - Bosque Rua Dom Pedro I.

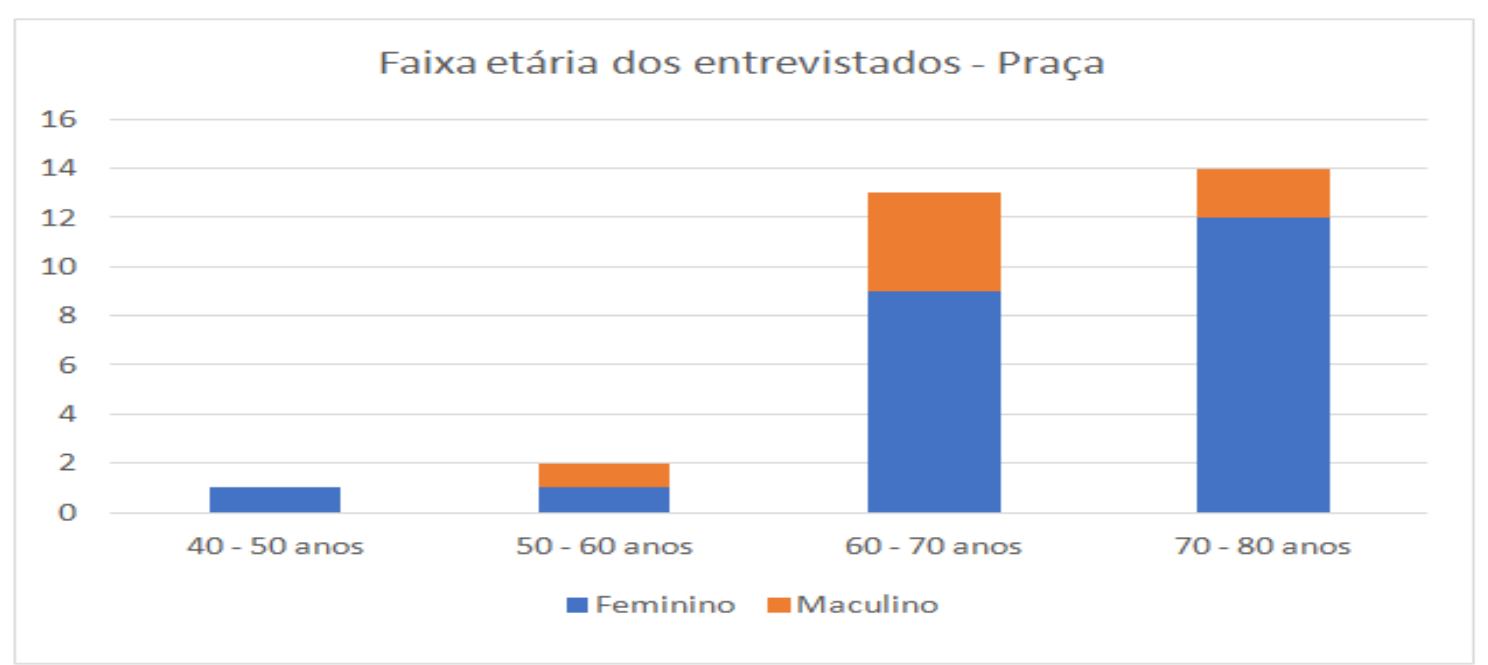

Figura 5. Faixa etária dos entrevistados - Praça 15 de Novembro.

As Figuras 6, 7 e 8 demonstram o tempo de residência dos os usuários entrevistados. Os dados encontrados variam dependendo da área de estudo. 0 Lago Municipal apresenta uma distribuição mais uniforme do tempo de residência uma vez que o espaço é frequentado pelos pioneiros do município, por indivíduos que moram há pouco tempo na cidade e por pessoas que moravam em outras cidades e atualmente residem em Palotina por cerca de alguns anos (Figura 6).

Na Praça 15 de Novembro, o tempo de residência está concentrado nos intervalos acima de 10 anos enquanto no Bosque da Rua Dom Pedro I, o maior número de apontamos está no intervalo abaixo de 10 anos. Os resultados podem estar relacionados ao fato dos moradores da Praça 15 de Novembro serem idosos que frequentam a "Praça do Vovô", os quais são moradores que acompanharam a trajetória da área verde e a evolução que o local teve durante esses anos. Alguns usuários relataram durante a aplicação dos questionários que, antigamente, existia um campo de futebol o qual era muito frequentado por esses idosos durante a vida adulta. Já o Bosque da Rua Dom Pedro I está localizado em um bairro mais recente e é frequentado por residentes desse bairro como será apresentado na Figura 10. 


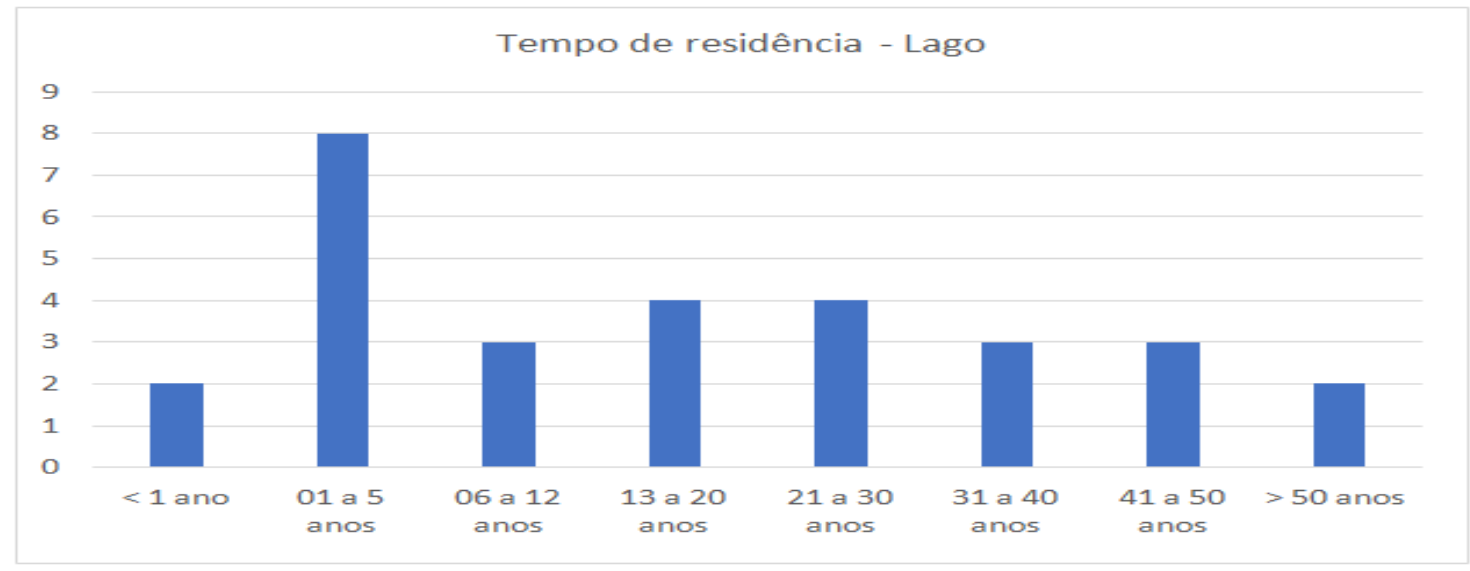

Figura 6. Tempo de residência - Lago Municpal.

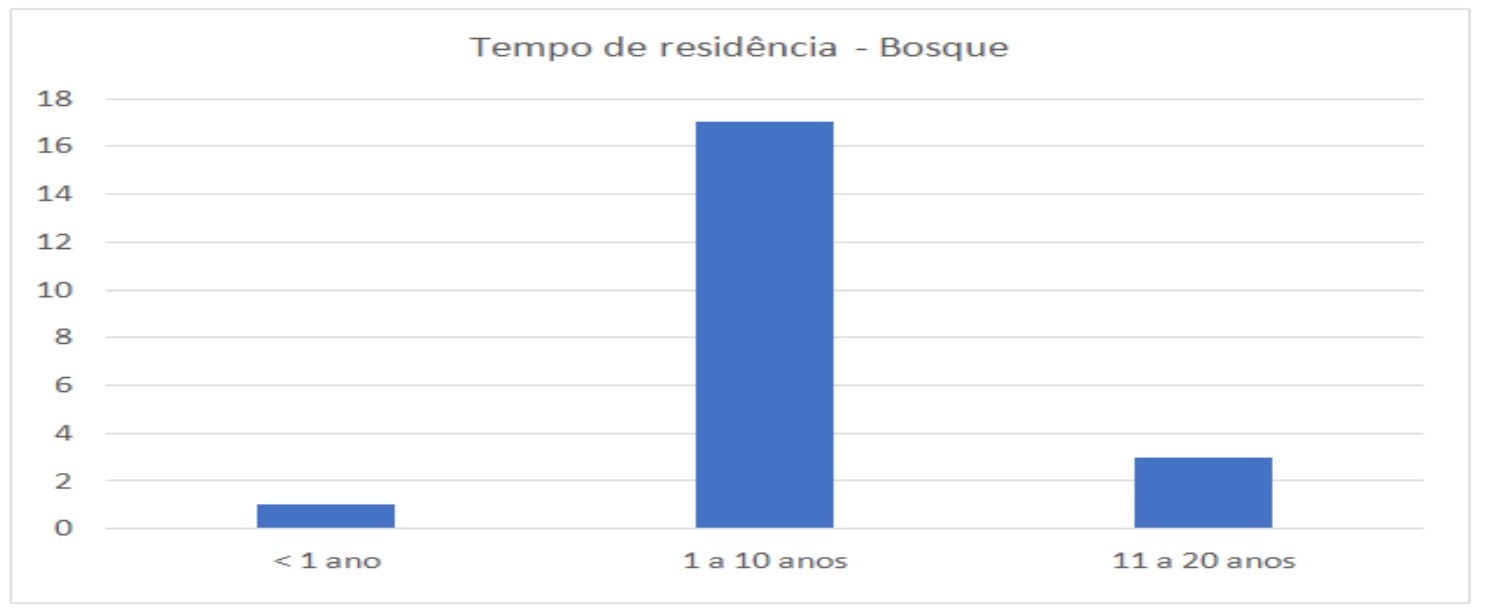

Figura 7. Tempo de residência - Bosque Rua Dom Pedro I.

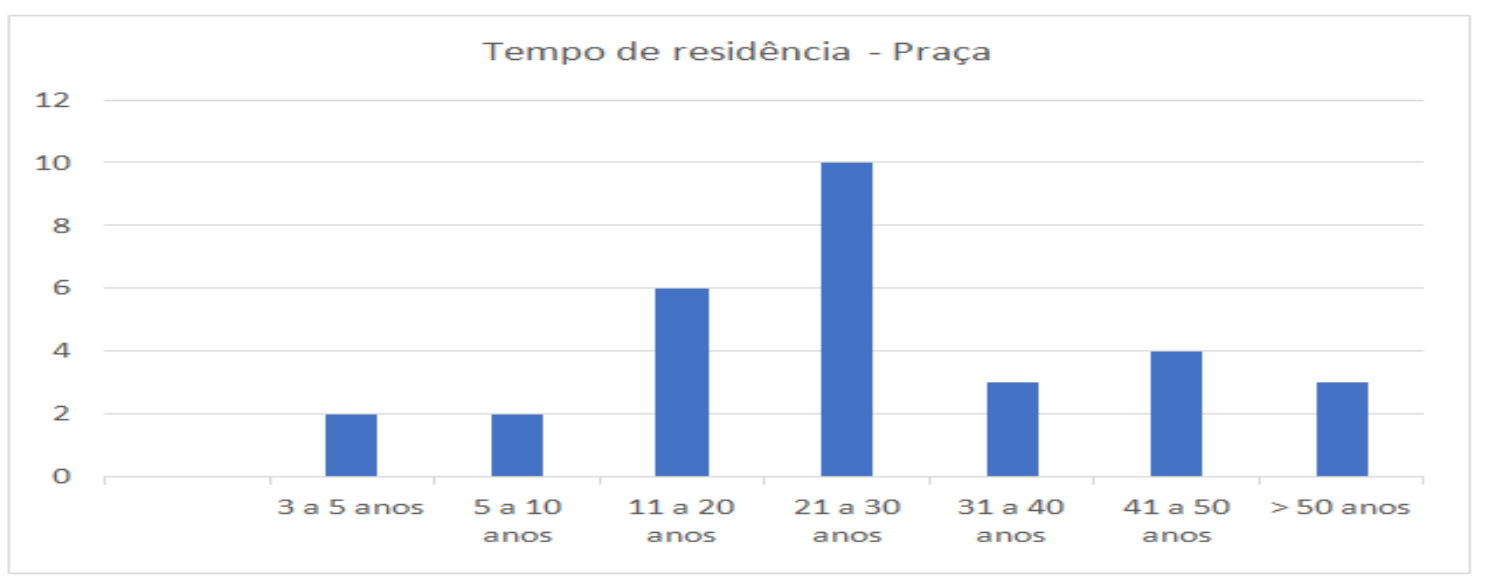

Figura 8. Tempo de residência - Praça 15 de Novembro. 
A distância da moradia dos entrevistados até a área verde também não foi uniforme entre os espaços estudados. Como demonstrado na Figura 9, o Lago Municipal é frequentado por residentes de diferentes bairros do município uma vez que há investimento público para atividades culturais e recreativas. Já no Bosque da Rua Dom Pedro I, a grande maioria dos entrevistados são vizinhos que residem há poucos metros e visitam a área diariamente para recreação e lazer (Figura 10). Os dois perfis são visualizados na Praça 15 de Novembro, ou seja, usuários que percorrem poucos metros e usuários que percorrem alguns quilômetros para frequentar o espaço (Figura 11).

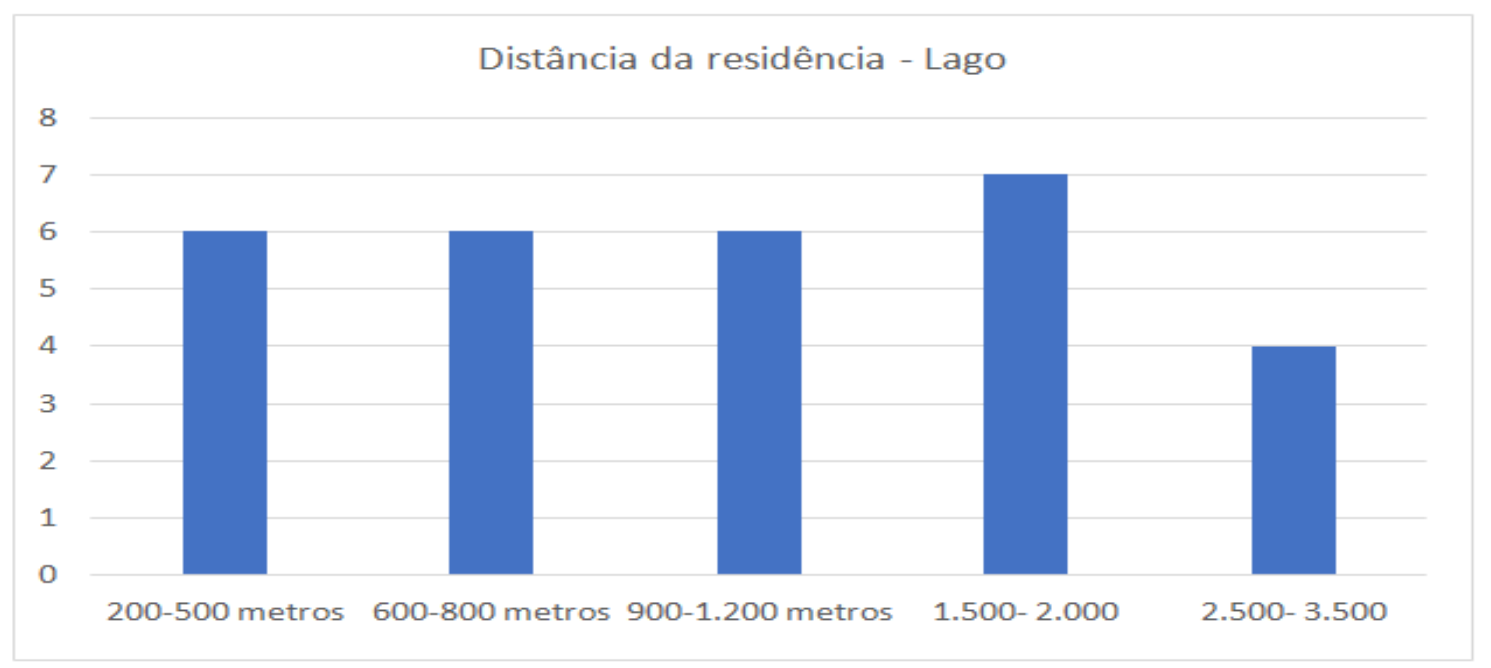

Figura 9. Distância da residência até o Lago Municipal.

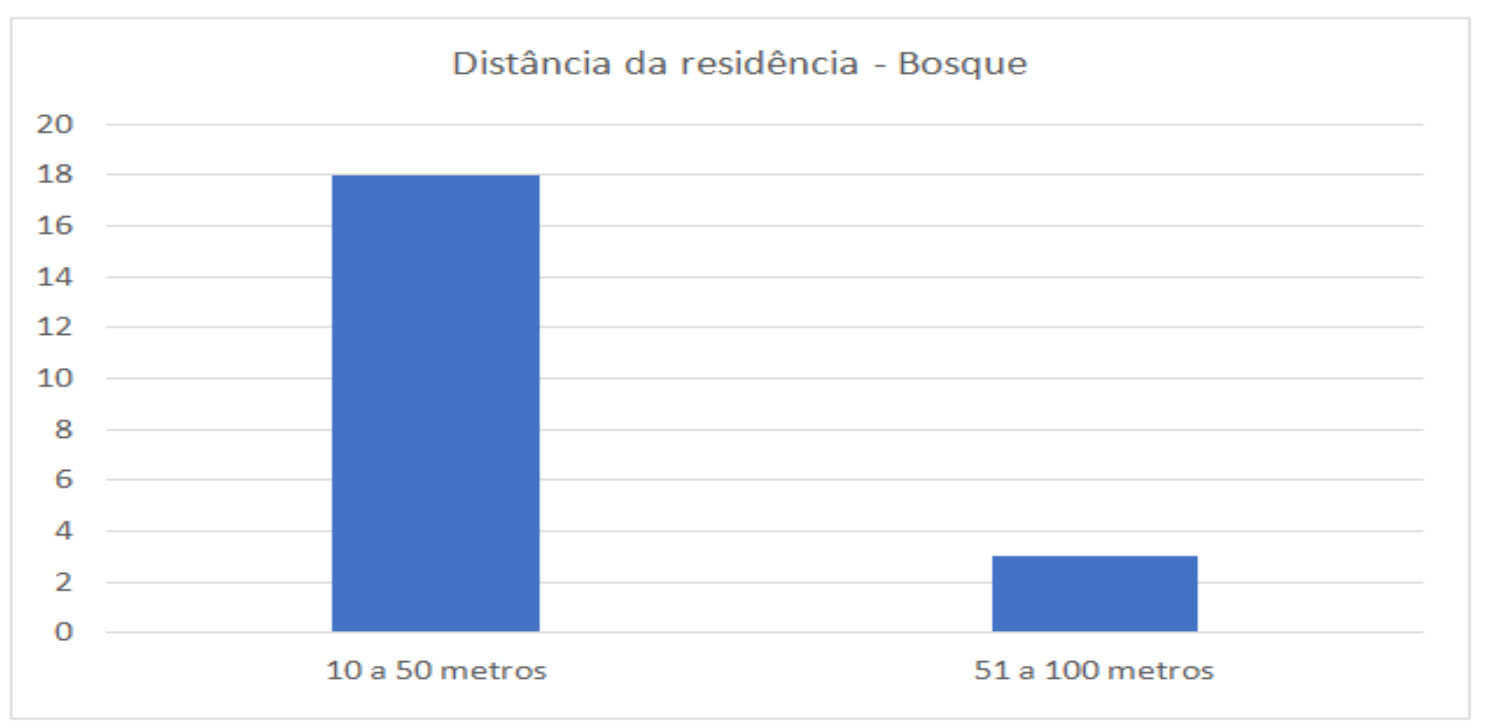

Figura 10. Distância da residência até o bosque da Rua Dom Pedro I 


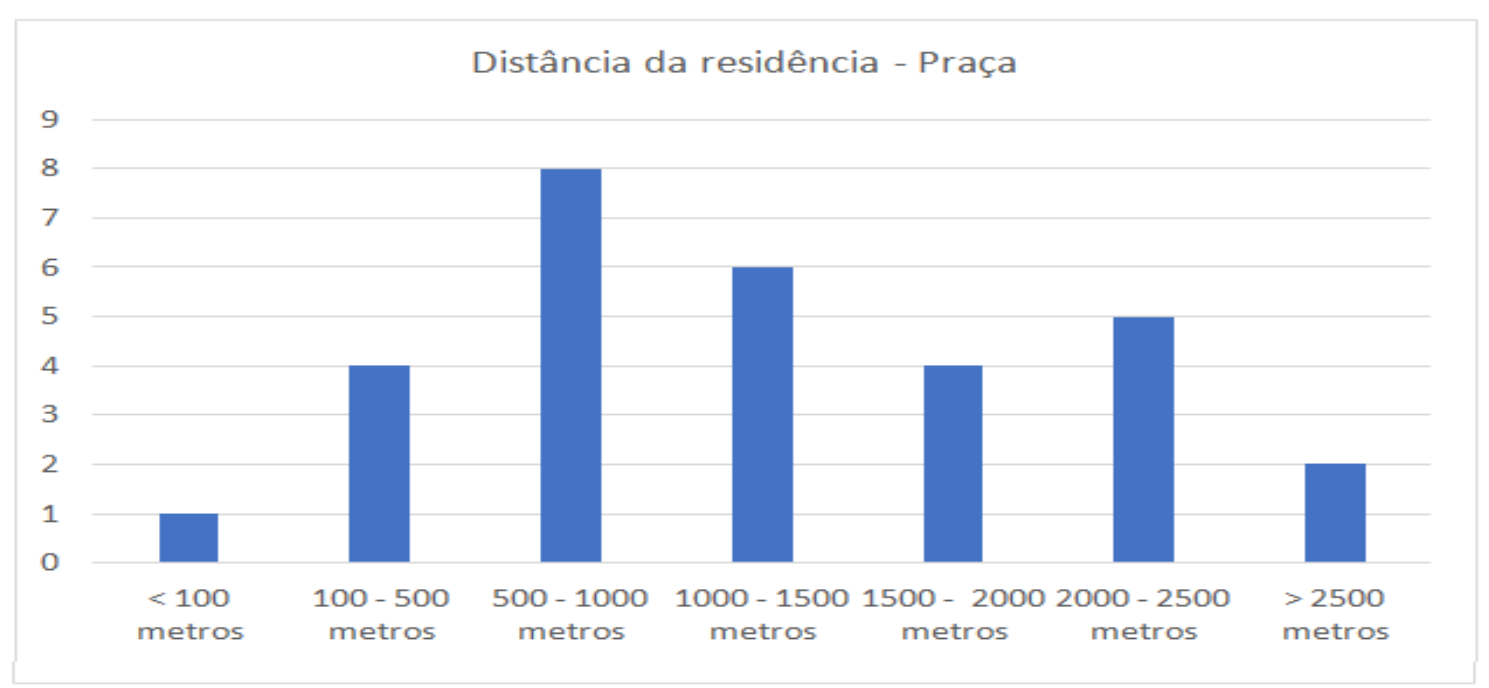

Figura 11. Distância da residência até a Praça 15 de Novembro.

Vários usuários ressaltaram que frequentam o Lago Municipal todos os dias ou vários dias da semana para práticas de exercícios, como por exemplo, caminhadas e corridas (Figura 12). A categoria diariamente se destacou no Bosque da Rua Dom Pedro I. Segundo os moradores, a frequência só não é diária em períodos chuvosos e no inverno. Esta periodicidade dos moradores leva a cuidados especiais com a área (como se esta fosse uma extensão de seus quintais), tais como, podas simples, plantio de mudas, recolhimento do lixo e contato com o Ministério Público para averiguar e resolver as não conformidades da área. Alguns entrevistados alegaram residir em outros bairros, mas por possuírem parentes no local usavam semanalmente ou mensalmente a área durante o convívio familiar (Figura 13). Por outro lado, na Praça 15 de novembro, a maioria dos entrevistados relataram frequentar uma vez por semana para as atividades sociais e culturais na sede do Clube do Vovô (Figura 14). As mulheres são as que mais frequentam a praça, realizando diversas atividades como a prática do yoga, academia ao ar livre e caminhadas.

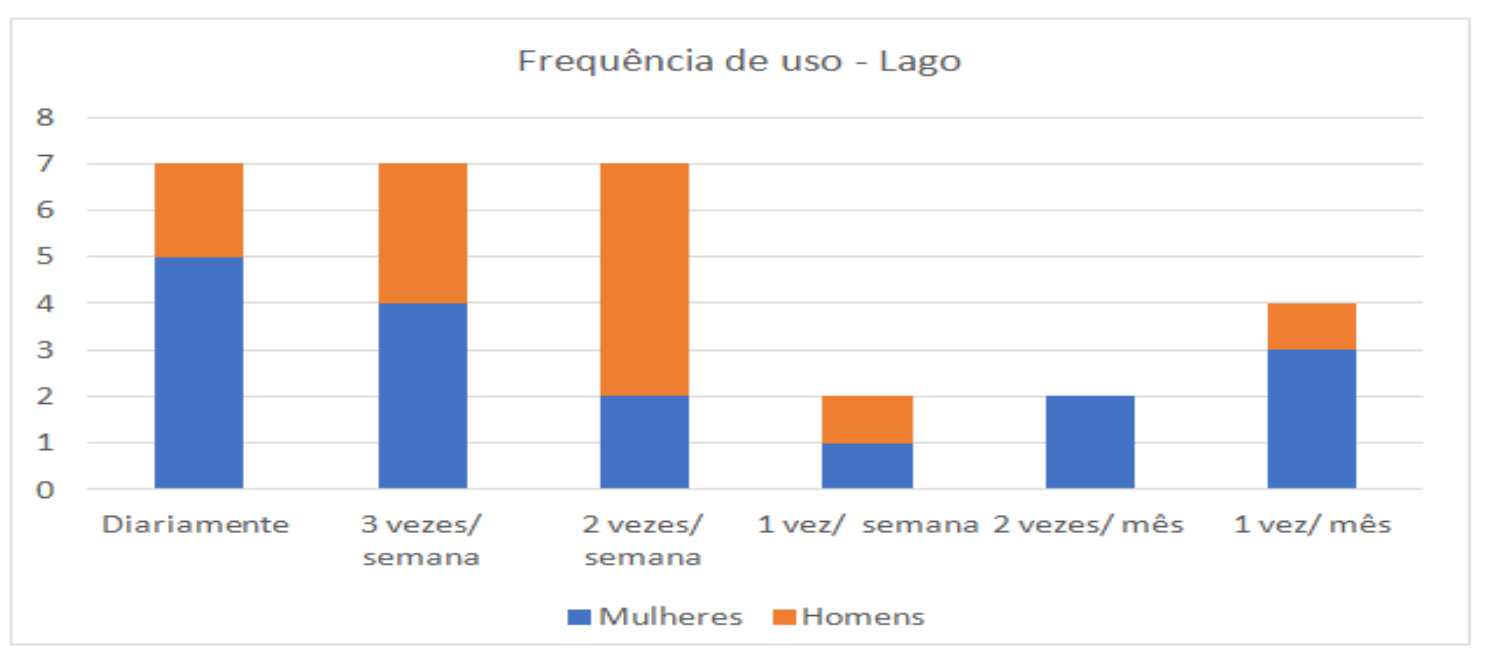

Figura 12. Frequência de uso do local - Lago Municipal. 


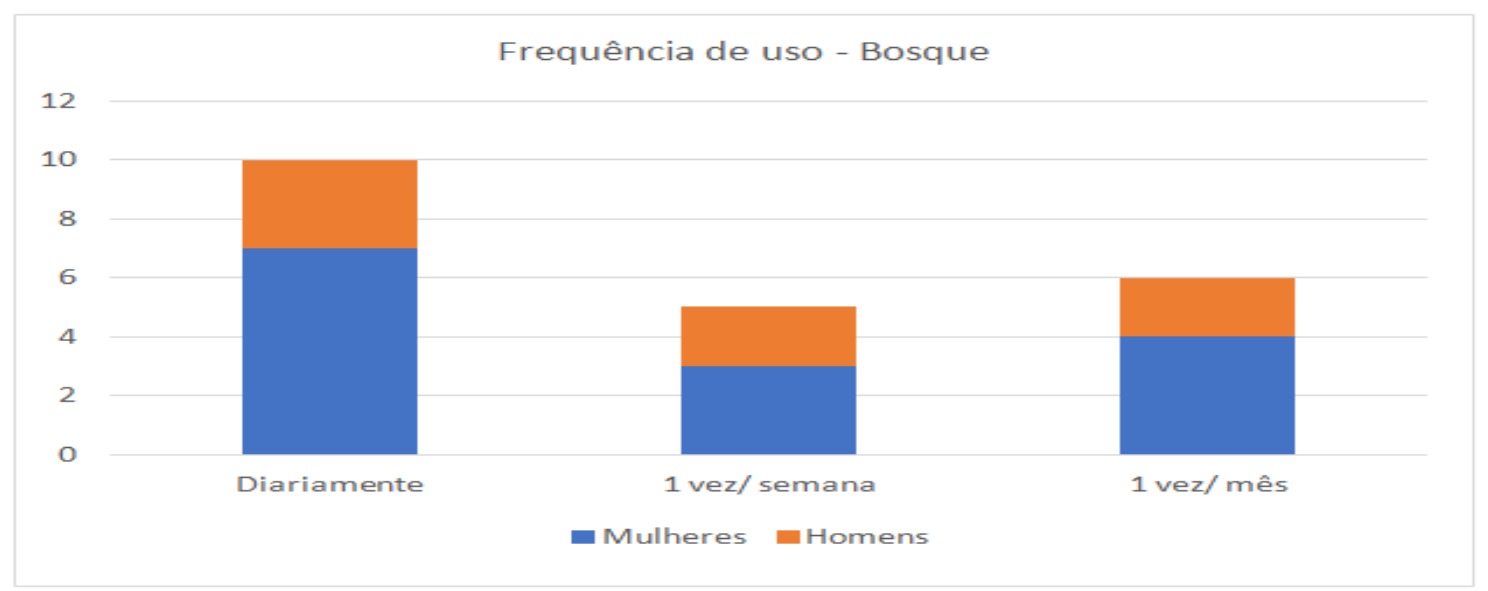

Figura 13. Frequência de uso do local - Bosque Rua Dom Pedro I.

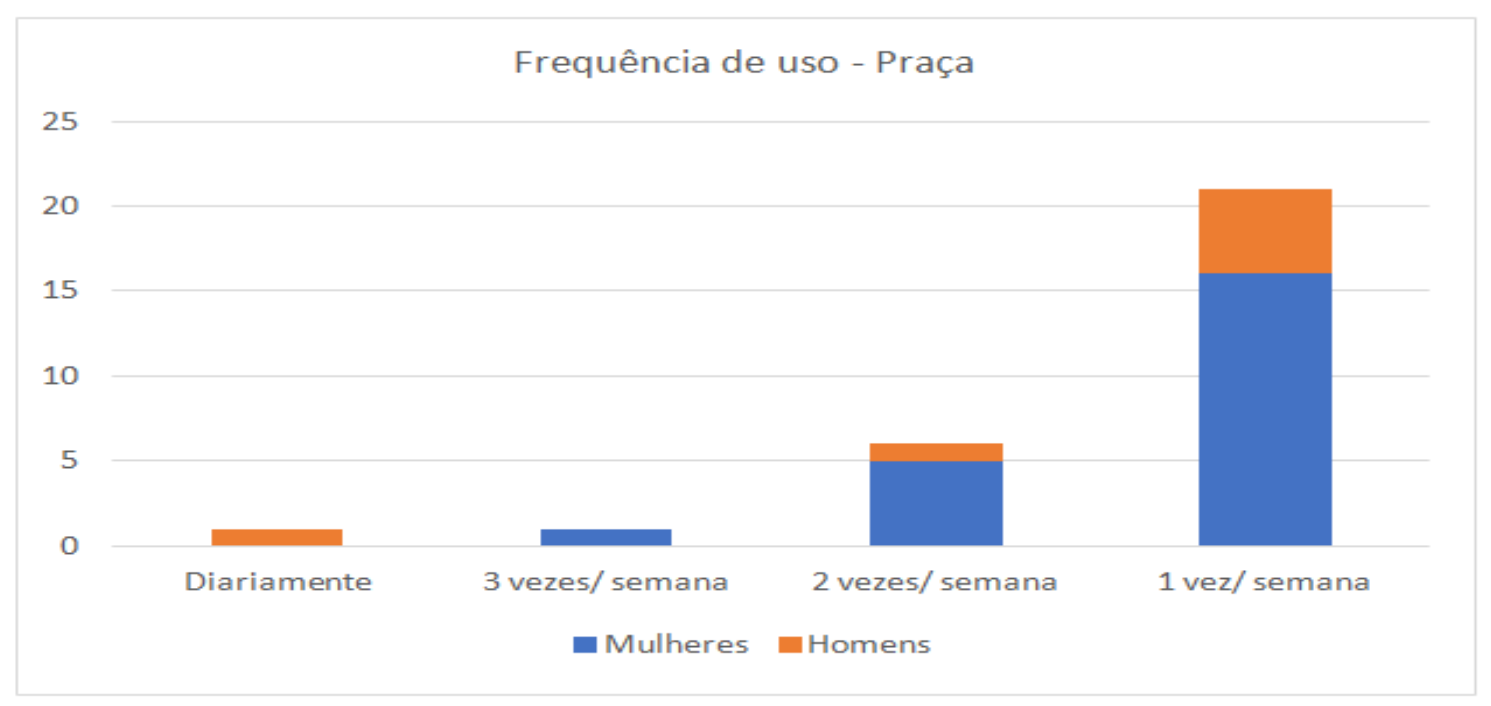

Figura 14. Frequência de uso do local - Praça 15 de Novembro.

No questionário aplicado, o entrevistado teria que mencionar qual aspecto de maior destaque na área. No Lago Municipal, os usuários mencionaram, em diversos apontamentos, o atributo "paisagens, cheiros e sons" como o principal, remetendo às árvores, grama, ao ar puro e à tranquilidade que o local proporciona (Figura 15). Esse atributo também foi destaque na Praça 15 de Novembro devido à grande quantidade de árvores no lugar (Figura 17). 0 apreço pela Praça também é identificado nas menções sobre as atividades físicas e culturais pela presença da academia ao ar livre e a sede do Clube do Vovô. Aspectos positivos também foram os mais apontados no Bosque da Rua Dom Pedro I, sendo que o atributo "futuro" e "lazer, atividades" foram os mais apontados (Figura 16). Esses resultados podem estar relacionados à presença de crianças que brincam rotineiramente no espaço. 


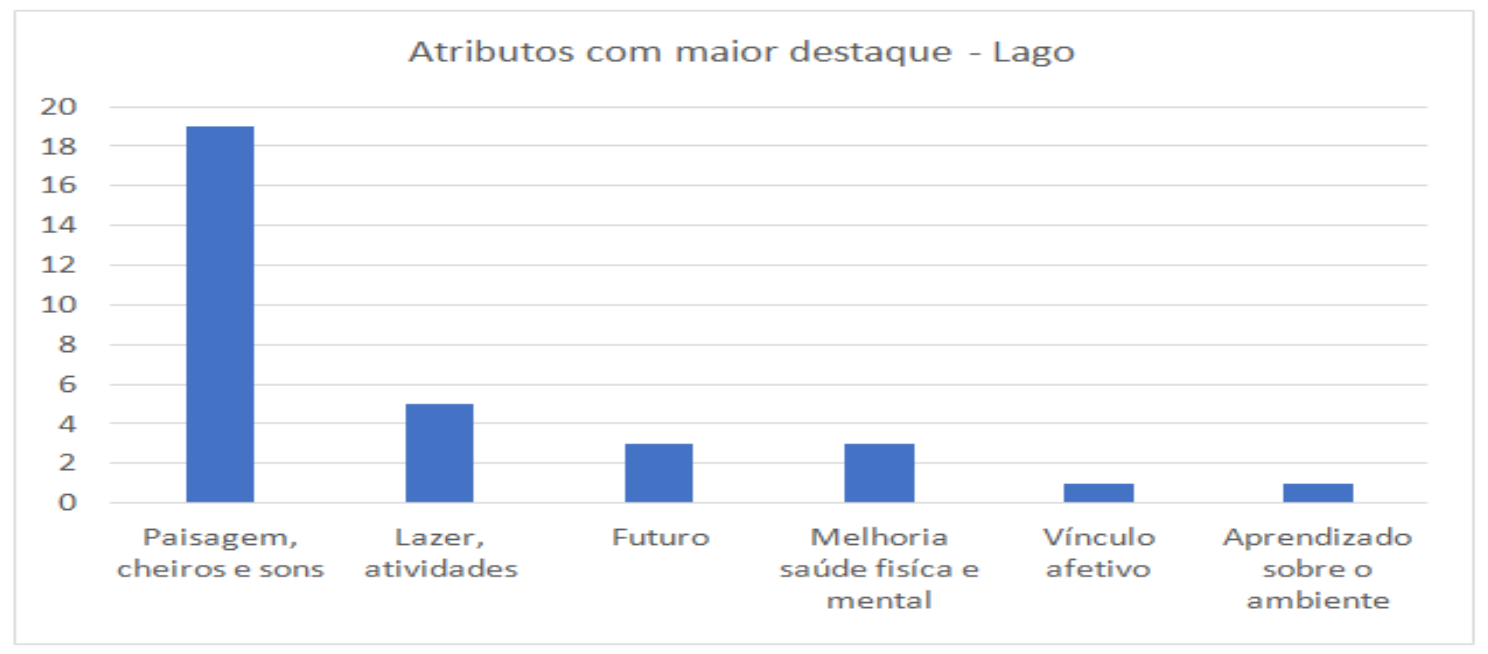

Figura 15. Atributos de maior destaque - Lago Municipal.

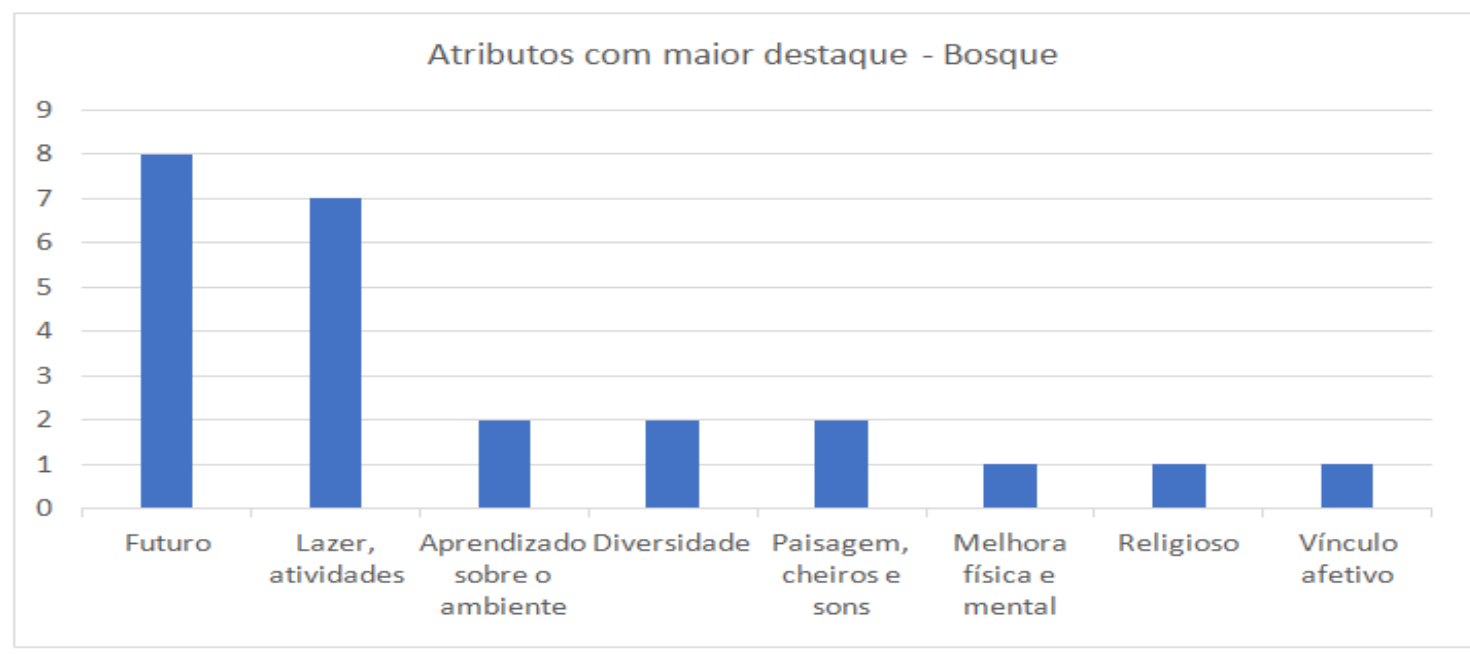

Figura 16. Atributos de maior destaque - Bosque Rua Dom Pedro I.

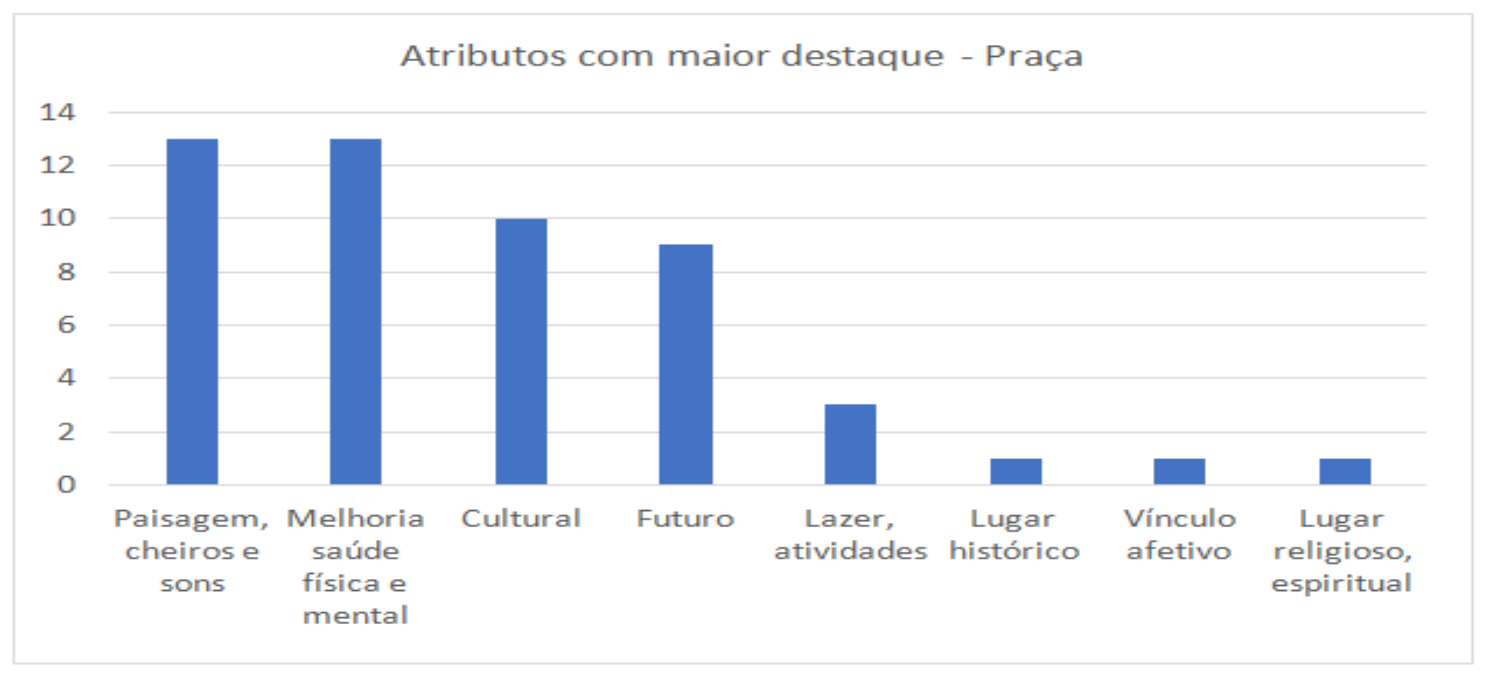

Figura 17. Atributos de maior destaque - Praça 15 de Novembro. 
As Tabelas 1, 2 e 3 mostram a quantidade de apontamentos de cada atributo nas diferentes sequências do rankeamento e se referem à ordem de valoração que os usuários das áreas escolheram para as cartas.

Tabela 1. Ordem de valoração das cartas - Lago Municipal.

\begin{tabular}{|c|c|c|c|c|c|c|c|c|c|c|c|c|}
\hline \multirow{2}{*}{ Atributo } & \multicolumn{12}{|c|}{ Posição } \\
\hline & 10 & $2^{-}$ & $3^{\circ}$ & $4^{\circ}$ & 5o & 60 & 7음 & $8^{\circ}$ & 9o & $10^{\circ}$ & $11 \frac{0}{}$ & $12^{\circ}$ \\
\hline 1 & 3 & 2 & 3 & 4 & 0 & 0 & 4 & 2 & 5 & 2 & 2 & 2 \\
\hline 2 & 4 & 3 & 1 & 1 & 1 & 4 & 2 & 4 & 1 & 2 & 3 & 3 \\
\hline 3 & 1 & 5 & 2 & 1 & 0 & 1 & 0 & 8 & 1 & 5 & 4 & 1 \\
\hline 4 & 3 & 2 & 2 & 3 & 3 & 1 & 3 & 5 & 3 & 2 & 1 & 1 \\
\hline 5 & 8 & 3 & 8 & 2 & 3 & 2 & 2 & 0 & 1 & 0 & 0 & 0 \\
\hline 6 & 1 & 3 & 4 & 4 & 2 & 6 & 6 & 1 & 1 & 0 & 0 & 1 \\
\hline 7 & 1 & 2 & 3 & 4 & 5 & 4 & 3 & 1 & 3 & 3 & 0 & 0 \\
\hline 8 & 1 & 2 & 2 & 2 & 3 & 2 & 2 & 4 & 6 & 1 & 2 & 2 \\
\hline 9 & 6 & 4 & 2 & 3 & 7 & 3 & 1 & 0 & 3 & 0 & 0 & 0 \\
\hline 10 & 0 & 0 & 0 & 0 & 1 & 2 & 3 & 0 & 1 & 7 & 6 & 9 \\
\hline 11 & 1 & 0 & 1 & 2 & 2 & 4 & 2 & 2 & 4 & 4 & 3 & 4 \\
\hline 12 & 0 & 3 & 1 & 3 & 2 & 0 & 1 & 2 & 0 & 3 & 8 & 6 \\
\hline
\end{tabular}

Legenda: Atributos: 1 - cultural, 2 - lugar histórico, 3 - alimentos e suprimentos, 4 - vínculo afetivo, 5 - melhoria física e mental, 6 - paisagens, cheiros e sons, 7 - aprendizado sobre o meio ambiente, 8 - futuro, 9 - lazer e atividades, 10 - extração e caça, 11 - diversidade, 12 - lugar religioso e espiritual.

Tabela 2. Ordem de valoração das cartas - Bosque Rua Dom Pedro I.

\begin{tabular}{|c|c|c|c|c|c|c|c|c|c|c|c|c|}
\hline \multirow{2}{*}{ Atributo } & \multicolumn{12}{|c|}{ Posição } \\
\hline & 10 & 2 o & 3o & $4^{\circ}$ & 5o & 60 & 70 & $8^{\circ}$ & 9o & $10^{\circ}$ & $11^{\circ}$ & $12^{\circ}$ \\
\hline 1 & 0 & 0 & 0 & 0 & 0 & 1 & 4 & 2 & 0 & 6 & 8 & 0 \\
\hline 2 & 0 & 0 & 0 & 0 & 0 & 1 & 1 & 2 & 3 & 5 & 7 & 2 \\
\hline 3 & 0 & 0 & 1 & 2 & 2 & 5 & 2 & 3 & 2 & 2 & 2 & 0 \\
\hline 4 & 0 & 3 & 2 & 2 & 3 & 1 & 5 & 2 & 2 & 0 & 1 & 0 \\
\hline 5 & 4 & 4 & 4 & 1 & 2 & 3 & 1 & 2 & 0 & 0 & 0 & 0 \\
\hline 6 & 1 & 0 & 5 & 3 & 2 & 5 & 2 & 0 & 2 & 1 & 0 & 0 \\
\hline 7 & 4 & 6 & 0 & 4 & 3 & 0 & 2 & 2 & 0 & 0 & 0 & 0 \\
\hline 8 & 6 & 2 & 2 & 5 & 3 & 1 & 0 & 1 & 1 & 0 & 0 & 0 \\
\hline 9 & 4 & 3 & 4 & 4 & 0 & 2 & 2 & 1 & 0 & 1 & 0 & 0 \\
\hline 10 & 0 & 0 & 0 & 0 & 0 & 0 & 0 & 0 & 0 & 0 & 2 & 19 \\
\hline 11 & 1 & 4 & 1 & 0 & 3 & 0 & 2 & 2 & 5 & 3 & 0 & 0 \\
\hline 12 & 1 & 0 & 2 & 0 & 2 & 2 & 2 & 5 & 3 & 2 & 2 & 0 \\
\hline
\end{tabular}

Legenda: Atributos: 1 - cultural, 2 - lugar histórico, 3 - alimentos e suprimentos, 4 - vínculo afetivo, 5 - melhoria física e mental, 6 - paisagens, cheiros e sons, 7 - aprendizado sobre o meio ambiente, 8 - futuro, 9 - lazer e atividades, 10 - extração e caça, 11 - diversidade, 12 - lugar religioso e espiritual. 
Tabela 3. Ordem de valoração das cartas. Praça 15 de Novembro.

\begin{tabular}{|c|c|c|c|c|c|c|c|c|c|c|c|c|}
\hline \multirow{2}{*}{ Atributo } & \multicolumn{10}{|c|}{ Posição } \\
\cline { 2 - 14 } & $\mathbf{1} \mathbf{o}$ & $\mathbf{2} \mathbf{o}$ & $\mathbf{3}^{\mathbf{o}}$ & $\mathbf{4} \mathbf{o}$ & $\mathbf{5} \mathbf{o}$ & $\mathbf{6} \mathbf{0}$ & $\mathbf{7} \mathbf{0}$ & $\mathbf{8} \mathbf{o}$ & $\mathbf{9} \mathbf{o}$ & $\mathbf{1 0}$ & $\mathbf{1 1}^{\mathbf{o}}$ & $\mathbf{1 2}^{\mathbf{o}}$ \\
\hline 1 & 2 & 2 & 2 & 2 & 3 & 1 & 4 & 3 & 4 & 3 & 2 & 1 \\
\hline 2 & 2 & 0 & 0 & 1 & 0 & 2 & 1 & 2 & 0 & 7 & 13 & 2 \\
\hline 3 & 3 & 0 & 2 & 5 & 1 & 5 & 0 & 3 & 7 & 3 & 3 & 1 \\
\hline 4 & 2 & 5 & 2 & 2 & 5 & 3 & 3 & 2 & 2 & 4 & 0 & 0 \\
\hline 5 & 4 & 1 & 5 & 0 & 7 & 3 & 5 & 3 & 2 & 0 & 0 & 0 \\
\hline 6 & 0 & 4 & 1 & 2 & 3 & 7 & 1 & 3 & 3 & 2 & 4 & 0 \\
\hline 7 & 5 & 2 & 4 & 3 & 1 & 0 & 6 & 6 & 3 & 1 & 0 & 0 \\
\hline 8 & 0 & 5 & 4 & 5 & 3 & 0 & 1 & 2 & 1 & 4 & 1 & 1 \\
\hline 9 & 4 & 5 & 3 & 2 & 3 & 3 & 2 & 2 & 3 & 2 & 1 & 0 \\
\hline 10 & 0 & 0 & 0 & 0 & 0 & 0 & 1 & 2 & 0 & 1 & 2 & 24 \\
\hline 11 & 1 & 2 & 3 & 5 & 3 & 2 & 4 & 2 & 3 & 2 & 2 & 1 \\
\hline 12 & 7 & 4 & 4 & 3 & 1 & 4 & 2 & 0 & 2 & 1 & 2 & 0 \\
\hline
\end{tabular}

Legenda: Atributos: 1 - cultural, 2 - lugar histórico, 3 - alimentos e suprimentos, 4 - vínculo afetivo, 5 - melhoria física e mental, 6 - paisagens, cheiros e sons, 7 - aprendizado sobre o meio ambiente, 8 - futuro, 9 - lazer e atividades, 10 - extração e caça, 11 - diversidade, 12 - lugar religioso e espiritual.

A carta de atributo que mais se destacou no Lago Municipal foi a "12- lugar religioso, e espiritual". E em segundo lugar, as cartas que mais apareceram foram: "8- futuro, 1- cultura, 3- alimentos e suprimentos, 11- diversidade". No Bosque, observouse que os atributos que mais aparecem nas duas primeiras posições são os "futuro" e "aprendizado sobre o ambiente" enquanto na Praça 15 de novembro, as cartas "12- lugar religioso e espiritual, "4-vínculo afetivo", "8- futuro" e "9- lazer, atividades" aparecem nas primeiras posições. Em todas as áreas estudadas, o atributo "10-extração e caça" recebeu poucos apontamentos, ocupando as últimas posições no rankeamento.

\section{Discussão}

No presente estudo, foi possível observar que as mulheres são as que mais utilizam as áreas verdes não apenas para exercícios físicos, mas também para lazer e convívio social, enquanto os homens não frequentam com a mesma intensidade. Outros estudos identificaram perfil semelhante, como o de Cassou (2009) ao apontar que as mulheres são mais conscientes quanto a importância das práticas de exercícios físicos rotineiros, como caminhadas e yoga. Szeremeta e Zannin (2013) relacionaram a qualidade do ambiente (como segurança, por exemplo) com o aumento de proporção de mulheres e pessoas mais velhas nesses locais.

De fato, o público idoso também foi evidenciado nesse estudo. 0 trabalho de Miranda et al. (2005) apresenta dados que explicitam o interesse dos idosos em participar das atividades nas áreas verdes próximas a suas residências. Giehl et al. (2012) realizaram a avaliação da prática de atividades físicas e percepção do ambiente pelos idosos e concluíram que idosos residentes perto de áreas de lazer como trilhas, vias e ciclovias praticavam mais atividades físicas, sendo esses lugares importantes para o incentivo da conduta ativa da população idosa. Balsan et al. (2006) estudaram a apropriação dos espaços de lazer (públicos, privados ou associativos) dos grupos de idosos de Rio Claro-SP e, mesmo existindo problemas de infraestrutura, os participantes relataram uma relação positiva com o lugar ao frequentá-lo para suas atividades cotidianas. Não obstante, o mesmo trabalho identificou a presença muito significativa de mulheres idosas em 
comparação ao número de homens idosos, aspecto que está em consonância com os dados desse estudo conforme supracitado.

Além dos adultos, o local é bastante frequentado pelas crianças. As áreas arborizadas propiciam brincadeiras ao ar livre e estimulam as crianças a interagir com o meio ambiente, aspecto considerado como fundamental para socialização, criatividade e desenvolvimento motor e fisiológico em vários estudos (Wells, 2000; Barros e Virgílio, 2003; Beery e Jørgensen, 2018). Mazzei et al. (2007) afirmam que estes espaços livres atuam como espaços com funções recreativas, educativas, ecológicas e estéticas, os quais são aspectos relevantes para o desenvolvimento infantil.

Apesar da distância da residência e da frequência de uso variar entre as áreas, os resultados apontam que a população usufrui rotineiramente dos espaços analisados. Essa periodicidade, além de revelar a importância das áreas verdes para esses usuários, aponta que a variável distância não é um fator limitante, muito provavelmente, por ser município pequeno. Silva (2017) comenta que um dos problemas encontrados nas grandes metrópoles é o deslocamento até as áreas verdes e que isso impede que grande parte da população frequente esses lugares por motivos como: trânsito, distância, tempo, insegurança, entre outros.

De forma geral, os usuários entrevistados demonstram grande apreço pelas três áreas verdes urbanas investigadas, o que remete ao sentimento de topofilia presente de maneira significativa no presente estudo. Isto pode ser visto tanto pelos atributos mais identificados nas respostas abertas, como no rankeamento de valoração ambiental.

Tuan (1983) ressalta que perceber/sentir algum lugar, acontece através de diversas experiências, que são vivenciadas cotidianamente no decorrer dos anos. 0 mesmo autor indaga que situações importantes na vida de cada pessoa a leva à associação com o lugar, em que o afeto está conectado ao tempo de convivência com o espaço, contendo bagagem emocional que explica a identidade do "eu". Da mesma maneira, os dados coletados revelam o vínculo afetivo, histórico e de identidade que os usuários têm com as áreas verdes investigadas.

Rêgo e Fernandes (2012) realizaram um estudo com o objetivo de compreender a percepção que os moradores da cidade de Coimbra (Portugal) sobre a importância do meio natural para a qualidade de vida citadina. Como resultado, o autor trouxe a topofilia como característica central na análise, considerando que o sentimento topofílico deve ser garantido de forma intencional. Para tanto, os autores argumentam sobre o papel das autoridades públicas em empenhar-se para trazer o verde nas cidades, propiciando mais arborização e a instalação de parques e praças e levando os cidadãos, mesmo que inconscientemente, a compreender as áreas verdes urbanas como "paisagem terapêutica".

Nos aspectos analisados, os resultados são específicos para cada local devido às características e funções de cada área verde. Todavia, os dados apontam que todas podem ser consideradas como primordiais para o contato com a natureza, para a qualidade de vida e para as funções sociais no município (atividades físicas, culturais, recreativas e educativas).

\section{Considerações finais}

0 presente estudo trouxe importantes reflexões acerca de como as áreas verdes urbanas são percebidas pelos residentes de Palotina. Estudos desse cunho subsidiam programas e políticas públicas em educação e gestão ambiental, fator relevante já que a região é carente de investigações com essa temática. Este estudo pode ser ampliado, explorando outras técnicas de coleta de dados, maior tempo de permanência em campo e diferentes abordagens teórico-metodológicas. 


\section{Agradecimentos}

As autoras agradecem aos residentes do Município de Palotina por aceitarem contribuir com esta pesquisa e à Prefeitura Municipal de Palotina por ceder a imagem utilizada na Figura 2.

\section{Conflito de interesses}

As autoras declaram não haver conflitos de interesse.

\section{Referências}

Alves, V. A.; Mendes, L. O.; Iared, V. G. Classificação qualitativa das áreas verdes urbanas de Palotina (PR) em relação às funções sociais e ecológicas. Educação Ambiental em Ação, v. 17, n. 64, p. 31-51, 2018.

Balsan, R.; Gerardi, L. H. O.; Queiroz, O. T. M. M. Os grupos de idosos de Rio Claro, SP: espaços e atividades. In: Gerardi, L. H. 0.; Carvalho, P. F. (Org.). Geografia: ações e reflexões. Rio Claro: UNESP/IGCE, AGETEO, 2006.

Bargos, D. C.; Matias, L. F. Áreas verdes urbanas: um estudo de revisão e proposta conceitual. Revista da Sociedade Brasileira de Arborização Urbana, v. 6, n. 3, p. 172188, 2011. https://doi.org/10.5380/revsbau.v6i3

Barros L. H. V.; Silva, V. P.; Alves, G. A.; Pinheiro, L. G.; Nascimento, I.; Dias, P. K. L.; Oliveira, R. F. A.; Santana, V. A.; Oliveira, W. A.; Medeiros, C. S. C.; Gomes, B. S. F. F. Diagnóstico das áreas verdes públicas do Bairro Potengi, Natal-RN. Holos, v. 5, n. 31, p. 130-141, 2015. https://doi.org/10.15628/holos.2015.3036

Barros, M. V. F.; Virgílio, H. Praças: espaços verdes na Cidade de Londrina. Geografia, v. 12, n. 1, p. 533-544, 2003. https://doi.org/10.5433/2447-1747.2003v12n1p533

Beery,T.; Jørgensen, K. A. Children in nature: Sensory engagement and the experience of biodiversity. Environmental Education Research, v. 24, n. 1, p. 13-25, 2008. https://doi.org/10.1080/13504622.2016.1250149

Belusso, D.; Serra, E. Caracterização sócio-espacial da agricultura no oeste paranaense: um estudo de caso em Palotina-PR. Agrária, n. 4, p. 20-29, 2006. https://doi.org/10.11606/ issn.1808-1150.v0i4p20-39

Brasil. Lei no 12.651, de 25 de maio de 2012. Dispõe sobre a proteção da vegetação nativa; altera as Leis $\mathrm{n}^{\mathrm{os}}$ 6.938, de 31 de agosto de 1981, 9.393, de 19 de dezembro de 1996, e 11.428, de 22 de dezembro de 2006; revoga as Leis $\mathrm{n}^{\text {os }} 4.771$, de 15 de setembro de 1965, e 7.754, de 14 de abril de 1989, e a Medida Provisória no 2.166-67, de 24 de agosto de 2001; e dá outras providências. Disponível em: <http://www.planalto.gov.br/ ccivil_03/_ato2011-2014/2012/lei/l12651.htm>. Acesso em: 26 maio 2019.

Brasil. Lei no 10.257, de 10 de julho de 2001. Regulamenta os artigos 182 e 183 da Constituição Federal, estabelece diretrizes gerais da política urbana e dá outras providências. Disponível em: <http://www.planalto.gov.br/ccivil_03/leis/leis_2001/ 110257.htm>. Acesso em: 26 maio 2019.

Cabral, P. I. D. Arborização urbana: problemas e benefícios. Revista Especialize, v. 1, n. 6, p. 1-15, 2013. 
Carbone, A. S.; Coutinho, S. M. V.; Tomerius, S.; Philippi Junior, A. Gestão de áreas verdes no Município de São Paulo: ganhos e limites. Ambiente \& Sociedade, v. 18, n. 4, p. 201-220, 2015. https://doi.org/10.1590/1809-4422ASOC1210V1842015

Cassou, A. C. N. Características ambientais, frequência de utilização e nível de atividade física dos usuários de parques e praças de Curitiba, PR. Curitiba: Universidade Federal do Paraná, 2009 (Dissertação de mestrado).

Costa, R. G. S.; Colesanti, M. M. A contribuição da percepção ambiental nos estudos das áreas verdes. RA'EGA, v. 22, p. 238-251, 2011. https://doi.org/10.5380/raega. v22i0.21774

Giehl, M. W. C.; Schneider, I. J. C.; Corseuil, H. X.; Benedetti, T. R. B.; D’Orsi, E. Atividade física e percepção do ambiente em idosos: estudo populacional em Florianópolis. Revista Saúde Pública, $\quad$ v. 46 n. 3 , p. 516-525, 2012. https://doi.org/10.1590/S003489102012005000026

Londe, P. R.; Mendes, P. C. A influência das áreas verdes na qualidade de vida urbana. Hygeia - Revista Brasileira de Geografia Médica e da Saúde, v. 10, n. 18, p. 264-272, 2014.

Marin, A. A. Pesquisa em educação ambiental e percepção ambiental. Pesquisa em Educação Ambiental, v. 3, n. 1, p. 203-222, 2008. https://doi.org/10.18675/2177580X.vol3.n1.p203-222

Mazzei, K.; Colesanti, M.; Santos, D. Áreas verdes urbanas, espaços livres para o lazer. Sociedade \& Natureza, v. 19, n. 1, p. 33-43, 2007.

Mellazo, G. C. A percepção ambiental e educação ambiental: uma reflexão sobre as relações interpessoais e ambientais no espaço urbano. Olhares \& Trilhas, v. 6, n. 1, p. 45-51, 2005. Disponível em: <http://www.seer.ufu.br/index.php/olharesetrilhas/article/view/3477/ 2560>. Acesso em: 26 maio 2019.

Minayo, M. C. S. 0 desafio do conhecimento: pesquisa qualitativa em saúde. São Paulo: Hucitec, 2000.

Miranda, S. E.; Modena, C. M.; Schall, V. T. Educação ambiental: conceitos e ações de idosos do grupo renascer em são José de Almeida, Jaboticatubas, MG. Anais do V Encontro Nacional de Pesquisa em Educação em Ciências, Bauru, p. 1-11, 2005. Disponível em: <https://www.arca.fiocruz.br/handle/icict/16299>. Acesso em: 26 maio 2019.

Mucelin, C. A.; Bellini, M. Lixo e impactos ambientais perceptíveis no ecossistema urbano. Sociedade \& Natureza, v. 20, n. 1, p. 111-124, 2008. https://doi.org/10.1590/S198245132008000100008

ONU - Organização das Nações Unidas. 2019. Disponível em: <https://nacoesunidas.org/ no-dia-mundial-das-cidades-onu-propoe-debate-acerca-dos-desafios-da-urbanizacaoglobal/>. Acesso em: 10 jan. 2020.

Palotina. Lei Complementar no 157, de 22 de agosto de 2019. Altera e revisa o Plano Diretor Municipal e estabelece diretrizes para o desenvolvimento participativo abrangendo todo o território municipal, e dá outras providências relativas ao planejamento e gestão, nos termos da Lei Federal no 10.257/2001. Disponível em: <http://www.palotina.pr.gov.br/servicos/plano-diretor/lei-complementar-1572019-c1921>. Acesso em: 26 nov. 2019. 
Pedrosa, J. A. G.; Gaia, M. C. M. Caracterização dos usos e funções de duas áreas verdes públicas urbanas no Município de Nova Lima, Minas Gerais. Acervo da Iniciação Científica, n. 2, 24 p., 2014. Disponível em: <https://www.metodista.br/revistas/revistasizabela/index.php/aic/article/view/515/412>. Acesso em: 26 nov. 2019.

Pereira, H. S.; Kudo, S. A.; Silva, S. C. P. Topofilia e valoração ambiental de fragmentos florestais urbanos em uma cidade amazônica. Ambiente \& Sociedade, v. 21, e01590, 2018. https://doi.org/10.1590/1809-4422asoc170159vu18l1ao

Rêgo, G. S. M. M.; Fernandes, J. L. J. A topofilia dos cidadãos para com o patrimônio natural urbano: o caso da Cidade de Coimbra. GeoTextos, v. 8, n. 1, p.11-32, 2012. https://doi.org/10.9771/1984-5537geo.v8i1.5495

Ribeiro, G. D. Valoração ambiental: síntese dos principais métodos. Rio Claro: Universidade Estadual de São Paulo, 2009 (Monografia de graduação).

Silva, S. R. A contribuição da infraestrutura verde para as cidades. Rio de Janeiro: Universidade Federal do Rio de Janeiro, 2017 (Dissertação de mestrado).

Szeremeta, B.; Zannin, P. H. T. A importância dos parques urbanos e áreas verdes na promoção da qualidade de vida em cidade. RA'EGA, v. 29, p. 177-193, 2013. https://doi.org/10.5380/raega.v29i0.30747

Tuan, Y. Topofilia: um estudo da percepção, atitudes e valores do meio ambiente. São Paulo: DIFEL, 1980.

Tuan, Y. Espaço e lugar: a perspectiva da experiência. São Paulo: DIFEL, 1983.

Wells, N. M. At home with nature: Effects of "greenness" on children's cognitive functioning. Environment \& Behavior, v. 32, n. 6, p. 775-795, 2000. https://doi.org/ $10.1177 / 00139160021972793$

Informação da Licença: Este é um artigo Open Access distribuído sob os termos da Licença Creative Commons Attribution, que permite uso irrestrito, distribuição e reprodução em qualquer meio, desde que a obra original seja devidamente citada. 